\title{
INVESTIGATING A SMART TECHNOLOGY
}

\author{
Kevin O’Sullivan, Karen Neville, and Ciara Heavin \\ Business Information Systems, University College Cork, Cork, Ireland
}

\begin{abstract}
Today's society is extremely apprehensive and cautious regarding security attacks with the result that identification and authentication have become a necessity. Sectors such as healthcare, education and transportation all require robust identification solutions and Smart-cards can deliver these solutions. The memory capacity and processing capabilities of the Smart-card make it vastly superior to competing technologies such as magnetic stripe cards, which are susceptible to such threats as 'skimming' and as a result are very insecure. Additionally, the data on the cards is often erased or corrupted by scratches or magnetic interferences. There are however many disadvantages to Smart-cards; such as the fact that both the cards and the infrastructure necessary can be costly. In order to be acknowledged as a standard and to enhance user acceptance of the cards, it requires a behavioural, on the part of the user, rather than technological change.

To date previous research studies have focused on Smart-card failures. However, this paper investigates the introduction of this Smart technology into an educational setting. Therefore the factors that affect its acceptance and use as well as the issues facing organizations and universities in adopting the technology are investigated. The paper provides a comprehensive analysis of the findings of the case through an illustration of the factors identified in relevant literature and those identified in the study (see Table 1) as well as unforeseen behavioral issues from the users such as a mass student protest against the use of the card.
\end{abstract}

Key words: Smart-card technology; innovation; user acceptance; security and education. 


\section{INTRODUCTION}

As the need for trust, authenticity and security in digital communications becomes ever greater, the case for robust identification solutions grows stronger [Katz et al., 2002]. This paper outlines how Smart-cards can deliver these solutions in an educational institution due to their inherent strengths focusing security among other factors. The benefits of the technology are discussed in the paper to explain why Smart-card technology is so an important for today's 'closed communities' and organizations. The advantages and disadvantages of Smart-cards are outlined to highlight the benefits that they can provide, as well as the disadvantages that may be hindering their acceptance and use. The reasons for the introduction of Smart-card technology are outlined and security will be argued as a reason why Smart-cards are utilized, by discussing the risks and issues involved and why security is so important and necessary for varied forms of operations; from accessing a building to conducting a financial transaction. Therefore, encryption and the levels used to combat security issues or threats are discussed to highlight the potential of the Smart-card to combat these threats. Additionally, the paper briefly explains the security risks that exist in conjunction with the Smart-card to illustrate that while the technology is an intrinsically secure device [Urien, 2000], it is not one hundred percent secure [McGraw et al., 1999]. Innovation diffusion theory is discussed, as Smart-card technology is viewed as relatively new, and a model of some of the factors affecting the acceptance of an innovation is examined. The paper concludes that there is a need to research Smart-card technology and the factors necessary for its acceptance and use. It argues the validity of the technology as well as possible factors that may be slowing its acceptance.

\section{THEORETICAL FOUNDATION}

Moore (1994) believed that for an organization, innovation is any product, input, process, service or technology that the organization perceives as new. Truman et al., (2003) claimed that Smart-card technology fits this description of an innovation as it is new to most individuals and organizations despite the fact that it has existed, albeit in various familiar forms such as telephone call cards. A popular model to explain and predict rates of IT innovation adoption is the diffusion of innovation theory (DOI) [Rogers, 1995], which aids new IT implementations. Rogers (1995) defines diffusion of innovations (DOI) as the process “....by which an innovation is communicated through certain channels over time among the members of the social system". The model identifies five essential characteristics that 
enhance the rate and effectiveness of diffusion as follows: (1) relative advantage, (2) compatibility, (3) complexity, (4) trialability and (5) observability. The first characteristic is the relative advantage of the innovation over the idea it replaces, including economic profitability, convenience and/or other benefits. The innovation is more likely to be accepted if it is perceived as providing advantages [Hebert \& Benbasat, 1994]. The second characteristic is the compatibility of the innovation with the existing values, past experiences and needs of the adopters. People are more likely to adopt technology if it is functionally compatible to those previously adopted [Dearing et al., 1994] and is consistent with the existing values, needs and past experiences of adopters [Rogers, 1995]. The third characteristic relates to the level of complexity or the ease with which an innovation can be understood. Finally, the fourth and fifth related characteristics are described as trial ability, or the degree to which adopters can implement an innovation, on an experimental basis and observability, or the extent to which results of an innovation are visible to others. Rogers's theory found that these five factors were dependent on the specific nature of the innovation but also on the specific characteristics of the adopting group. The people who do not trust technology, for example, are generally older, less educated and earn low salaries [Punishill \& Shevlin, 2001]. Research has shown that the perceived characteristics of an innovation are closely linked to adoption [Rogers, 1995], more so than the personal characteristics of the adopting group [Tornatzky \& Klein, 1982].

The value of innovative applications is dependent upon the adoption and acceptance by the relevant parties involved [Plouffe et al., 2001] such as the party implementing it and the intended users because if one of the groups resisted, then it could threaten the introduction of the innovation. The benefits derived from increased usage of a technology, can be seen in the use of the telephone for example. If it was not used, then what would be the point of someone adopting it as the users would have no one to establish a connection with, but as more people used the technology, the benefits of adopting the technology (the Phone) continued to increase. Truman et al., (2003) use this argument when explaining that Smart-cards technology is suffering from a similar fate as the benefits gained from Smart-cards will increase as more users adopt the card.

\section{$1.1 \quad$ Smart-cards}

A Smart-card is a "...credit card sized conventional plastic card", containing an embedded silicon computer chip (which can be a 
non/programmable microprocessor) [Blakey \& Saliba, 2000 ]. Di Giorgio (1998) describes it simply as a credit card with a 'brain', which allows a large amount of information to be stored, accessed and processed either on or off line [Choi et al., 1998]. Smart-cards are in fact differentiated by the type and size of integrated chip (IC) used by the manufacturer and the method of communication utilized to interact with Smart-card readers [Sorenson, 2001]. Smart-card technology has been in use since the early 1990s but it is still considered a relatively new technology by retailers, consumers and users [Truman et al., 2003]. It has many technological advantages over rival technologies, such as the magnetic stripe card, which includes: (1) security, (2) memory size, (3) portability, (4) convenience, (5) multiple applications, (6) cost savings and (7) micro-charging.

(1) The Security component incorporated into the design of Smart-cards provides a secure means of physically carrying information as it protects against '....the illegal use oflost or stolen cards, manufacture of counterfeit cards, the manipulation ofdata and fraudulent use of the card' [Newing, 1998]. Carrying Smart-cards are extremely secure through the use of multiple factor authentications [Perkins, 2002] so that both the card and a personal identification number (PIN) are required. This two factor authentication that the Smart-card possesses can considerably reduce fraud, ensuring the integrity and security of transactions, therefore saving millions [Wallis, 2002] for financial institutions. It can also be applied to the Internet where the security threats faced means identification and authentication are very important for trust [Pohlmann, 2001]. However, when used as a wallet Smartcards are like cash in that if they are lost the cash on the card is gone forever [McGraw, 1998]. The self-containment of the card makes them tamper resistant [Lett et al., 2002]. Cryptographic algorithms can be stored locally in their internal circuitry, unlike the magnetic stripe cards, therefore protecting and retaining the users' 'secrets' [M'Raihi \& Yung, 2001].

(2) Smart-cards provide a greater memory capacity than magnetic stripe cards which have a total storage of 125 bytes while the microchip on the Smart-card can hold large amounts of data ranging from $1 \mathrm{Kbps}$ to $64 \mathrm{Kbps}$ [Kapoor, 2002]. One benefit of this is the ability to track customer spending records [Miller, 2002]. The card can also physically separate data into a multi-partition file system, so that many applications can be safely run on a single Smart-card [Rastogi \& Das, 2002]. The extra memory can also allow them to utilize biometrics and encryption [Rastogi \& Das, 2002].

(3) Smart-cards are portable, making the card and the credentials they carry, such as private keys, very manageable [Berney, 2000]. The extra layer of security that the card provides means that users are not limited 
to a particular desktop computer [Coia, 2002]. However this user mobility is only possible if every machine that the user accesses has a Smart-card reader attached [Chadwick, 1999].

(4) Apart from the convenience added through their portability, smart-cards can also replace the various identification cards, notes and coins by combining them into a single card [Choi et al., 1998]. Smart-cards are ideal because of their convenience and ease-of-use [Lee et al., 2000] due to the use of a form (plastic card) that people are familiar with [Gemplus, 2003].

(5) The ability to handle multiple applications is one of the primary reasons for the cards growth. According to a study by Frost \& Sullivan (2003), '....smart-cards are the only token technology that provides multiapplication capability coupled with a multi-function form factor that is virtually ubiquitous'. Due to the processing power of smart-cards, the card is ideal to mix multiple functions, which can help organizations such as colleges or governments to manage and improve their operations at lower costs [Choi et al., 1998] and offer innovative services. The card allows companies to work with partners in other industries to provide complementary services and customers to enjoy more customised services that add convenience and ease of use. In fact, the interoperability or multi-application use is the way forward in terms of consumer acceptance [Alder, 2002].

(6) Smart-cards can have transaction cost savings over other stripe cards. When the card is read by an electronic reader the encryption devices validate and verify each other. The technology also allows transactions to be carried out off/online, eliminating the middleman as telephonic verification is no longer required for authorisation [Miller, 2002]. Smart-cards, unlike magnetic-stripe cards, can carry all necessary functions and information on the card and do not require access to remote databases at the time of the transaction [Coleman, 1998]. Smartcards can also reduce labor costs by eliminating paper and therefore paper handling which is especially important in paper heavy industries such as healthcare [Choi et al., 1998] or education.

(7) Smart-cards are ideal for micro-charging or payments such as small Internet purchases because cheques and credit cards are too expensive [Karppinen, 2000]. There is also a growing demand for an alternative to credit cards because children and young adults will not be able to gain access to the smart-card e-purse which can be used for micro-payments [Lee et al., 2000].

Essentially the technology, as outlined, offers numerous benefits to the different types of users. However as with every technology the Smart-card is susceptible to issues that affect user acceptance. 


\subsection{Disadvantages of Smart-card Technology}

Smart-cards, offer many incentives, however, the disadvantages arising from the technology must also be identified before its introduction into any environment. The following are some of the disadvantages of the technology: (1) cost, (2) privacy, (3) standardization, (4) consumer acceptance and critical mass and (5) multiple application issues. Each of the disadvantages identified are outlined in the next section:

(1) To avail of the technology, organizations need to deploy readers, which add to the cost of deployment and also limits the use of the cards to locations where the infrastructure is ready and available [Armstrong, 2001]. Currently, there is a lack of infrastructure to support Smart-cards. This is one of the greatest disadvantages for merchants due to the expensive cost of replacing former equipment with smart-card-compliant terminals as well as additional operating expenses and the cost of training employees [Manchester, 1997]. Increasing numbers of vendors and manufacturers are entering the Smart-cards market, which will force prices down [Christensen et al., 2001].

(2)One factor that is causing concern is privacy, especially as a single smartcard holds considerable information about its user and can create an audit trail of their transactions resulting in the loss of anonymity that existed with cash transactions [Beverly et al., 2002]. The information it stores is usually already available in some format or another and the card merely makes that information portable, available and in the possession of the owner [Wood, 2002]. Credit card information, for example, already includes an enormous amount of customer data based on preferences and habits [Wood, 2002].

(3) Standardization is vital to the development and acceptability of Smartcard technology [Banerjee, 1997] because according to the emerging markets theories [Day \& Fein, 2000] standard wars tend to slow down the diffusion of new technical innovations [Rogers, 1995]. Standardization and interoperability are crucial factors in achieving a critical mass of users [Papameletiou, 1999] and if they do not exist, it acts as deterrents to expanded Smart-card deployment [Frost \& Sullivan, 2003]. Due to the amount of Smart-card systems entering the market, Smart-cards interoperability is important because people do not want to carry more cards and have separate incompatible ways to use them [Mäntylä, 2001]. It is also important for the Smart-card application developers so that they do not have to deal with a variety of different card terminals and operating system languages when developing their applications. Smartcard operating systems are extremely important because with open operating systems there is no dependence on a single manufacturer or application developer leading to a greater choice of manufacturers and 
application developers [Chandak \& Shah, 2001] cost reduction, processing capabilities and most importantly, interoperability [Moll, et al., 2001] as multiple applications can reside on the same card.

(4) One of the biggest obstacles to the mass adoption of smart-cards is customer education. Most consumers do not know what they need or want until they actually have it [Wallis, 2002]. The use of a smart identification in organizations to provide access to both physical and digital resources will force employees to become accustomed to having their cards in their possession at all times. Education and advertising will be very important in changing people's habits and expectations of this new technology [Truman et al., 2003].

(5) Smart-cards are flexible and therefore can be used for different applications [Pohlmann, 2001] but responsibility in the case of a problem (technical or legal) with a multifunctional card providing several applications from different services is a dilemma. The issue of control of the card and how it is managed will and does cause concern.

Today, Smart-cards exist in one form or another in many different sectors and are a part of everyday life in areas such as banking, transportation, access and mobile communications. Smart-cards offer almost unlimited application possibilities and realise their true value when a single card handles multiple applications. There is a move towards the multi-application smart-card with the maturity of operating systems such as Java and Multos, and falling prices. According to Briney (2002), the multi-application capability of the smart-card is the single principal driver of its growth. Hovenga Fancher (1997) claims that the smart-cards will be a tool for addressing the 'customer ofone' with customisable generic cards eventually becoming available allowing the customer to choose from a menu of applications. The primary market or use of the card are communities or 'closed systems', such as universities or the military. These communities generally tend to be successful [Truman et al., 2003] as people are affiliated with them and there tend to be discounts or a lack of alternatives. This paper therefore investigates the adoption of the technology in an educational setting.

\section{RESEARCH OBJECTIVE AND APPROACH}

The objective of this research was to investigate the adoption of Smart-card technology in an educational environment considering the factors which affect its acceptance and use. The objective required the researchers to gain an in-depth understanding of Smart-card technology focusing on how the cards are deployed and utilized in an academic setting. Due to the qualitative 
and exploratory nature of this study, a single site case study was employed as the most appropriate research approach. Consequently, semi-structured interviews were conducted using a pre-constructed interview guide. The questions were prepared based on previous research in the area of Smartcard technology, the researchers found this approach to be adequately flexible, allowing the respondents to develop certain questions where necessary and to address areas that were not suggested in the guide but that they felt were pertinent to this research.

\section{BACKGROUND TO THE CASE- WIT}

Waterford Institute of Technology (WIT) is the sole provider of higher education in the South East region of Ireland, and has the highest number of third level students in the sector, with over 6,000 current full-time students and over 4,500 part-time students. The Auxiliary Services (AS) Committee at WIT controls all of the trading operations on campus with the aim of providing high quality non-academic services and facilities for the student population of WIT. Approximately seven and a half years ago, WIT made a decision to investigate the possibility of using Smart-cards for printing and photocopying due to the expense of paper handling. WIT initiated a research project where they researched the systems used in other colleges. For two years, WIT conducted onsite investigations and gathered research from other implementations in both American and European universities. WIT then created a final report with the best components from each University system that was suitable for an Irish environment. The college decided to employ their own team, and develop an in-house system. The photocopying and printing system was put in place two months later and the vending and pointof-sale over a period of two years. Currently, WIT has fifteen applications, running on their Smart-cards which the college developed in-house. Unfortunately there was not sufficient time to test the card initially as WIT were committed to introducing the card in September 1999, and also because the college felt it was very difficult to introduce it in a test situation primarily due to the fact that students would not take it seriously. Since then, any new application WIT introduces is accepted and implemented on a pilot basis. WIT succeeded in installing the entire project at no cost, sourcing finance and support from different sectors. A considerable benefit for the college was the introduction of the card for printing and photocopying as students had no other option but to use the card. When the college introduced vending and then point-of-sale in the restaurants, the students were already accustomed to the technology. 


\subsection{The WITCard}

The WITCard is one of twenty-six different services that the committee provides. It was introduced in September 1999, by AS, and it is the official identification card for both staff and students. It is a multifunctional card which has replaced all of the other cards in use by integrating various applications into one single card, namely the following: the library, college identification, printing, photocopying, point-of-sale, vending, access control and voice mail. The card allows cashless purchasing on campus where the card is used at any point-of-sale on the campus, such as the restaurants and campus shops. A bar code on the card is still used in the library to allow users to borrow books and journals. In the event of a charge for late return of books, the electronic purse can be used to make the appropriate payment. There is also an Internet Card Management System (Internet CMS), recently developed by WITCard Services, which allows the card holder to check their card balance, view and print statements of all transactions, deactivate their card, and change their password.

\subsection{Incentives for Use}

The college conducted a joint survey with Irish and British banks on the cost of handling cash. The results of the survey concluded that the cost was somewhere between twelve and fifteen percent. If a student or staff member uses their card on campus to buy items such as food or stationary, they will get a ten percent discount due to the reduction in the costs of handling cash. Therefore, the benefits from the savings are passed onto the card user in the form of discounts. The college has also received other huge savings such as labor costs and safety. The WIT library is also a cashless environment; the restaurant will not accept cash, only a card, eliminating problems with floats, or cash. Prior to the introduction of the WITCard, the college did not have many security systems in place. The card used by the college was just an identification card with a barcode printed on it. Essentially, there was no security and for safety reasons, students have much more faith carrying ecash as opposed to carrying cash. The PIN feature of the WITCard is not used except when security is required. Currently, the only place the PIN on the chip is used in the college is for access control to campus residences, to protect against thieves accessing those residences with stolen cards. Even when purchasing, at the tills there is no PIN as the manual entry of the PIN slows down the queue. While the facility is there for the PIN the college has not used it and they do not see the need to use it because they have not encountered any breach of security. Security has become an increasingly 
important issue for WIT and the college is using Smart-cards to deal with this issue. The Smart-cards is superior to the magnetic stripe in terms of security and makes students feel secure in the knowledge that user accounts will not be compromised and that students will not lose their money. Confidentiality, integrity, non-repudiation, and authentication are all key factors. At the moment WIT guarantee these factors as students are provided with back-office accounts. As EMV (a Europay, MasterCard, and Visa devised specification) develops and WIT incorporates an open electronic purse on the card and start using open payment systems such as Java cards, they will then have to utilize a very secure authentication system.

An additional advantage to the university is the increased productivity of their staff. For example, one simple benefit at the moment is modernising the 'clocking-in' systems. There was a 'Working Time Act', introduced in 1997, which obliged all employers by law to record the time and attendance of their employees. The act was implemented to stop claims by employees that their health had been damaged when they were forced to work more than the statutory forty-eight hours a week. In September 2003, all of WIT's nonlecturing staff, using their WITCard to access facilities, will have their time and attendance recorded and held on record for three years. For the students, the WITCard is extremely easy to use as well as portable, which means that they are not limited to any single location with the card. Students also have fewer cards to carry around as the WITCard is multifunctional and has replaced all of their other cards by integrating the various applications onto one single card. There is also the ten percent discount that the students get for using the card instead of cash. The college also promotes the WITCard as much as possible, and students can win prizes such as televisions and bicycles, by using the card at a particular time. This marketing strategy was very popular with both the students and staff, as every time they used the card they had a better chance of winning a prize.

\subsection{Difficulties Encountered}

The cost of the implementation was a very important factor for WIT, however once the college decided on a Smart-card system, they worked on ways of raising money to fund the project. The college selected a system, that was robust, that would actually handle magnetic stripe and allow migration of applications from the magnetic stripe to the chip. If WIT had not planned the migration from magnetic stripe to chip from the start of the project, the whole system would have had to be rebuilt. A lot of similar projects failed because they did not plan at the early stages for this change in technology two or three years later. As research has shown standardization 
is very important factor and WIT are currently working with colleges across Europe to develop standards for Universities and colleges so that there will be interoperability between them so that cards in one college should be able to work in another. The WITCard is compatible with standards such as common electronic purse specification (CEPS) and personal computer / Smart-cards (PC/SC) however these are not approved standards. There has to be an agreed standard under the International Standards Organization (ISO) which uses an accreditation system.

Training was part of the initial rollout and was provided and managed by AS. Courses were provided for the operators of the tills, as well as for students and staff. Students were even employed to tutor training courses and promote the card within the student population. AS also produced and provided promotional videos and pamphlets describing the card system. The college was expecting that in the second year of the introduction they would encounter resistance because in the first year the card was new and the students would view it as a novelty. At WIT, as their research had shown them, it was in the second year when the card actually started to take hold that the college experienced resistance from a group of the students for a period of about three months. More than 6,000 students organised by the students union, boycotted lectures at WIT for a day, in protest against the use of the new card system. The resistance centred on the fact that the card was expected to be insecure. Students also presumed that college management were reading the information stored in the back-office system, such as: where students were eating and what they purchasing, which, according to the college was not the case. When implementing change, there is always going to be resistance but it is important to target the core services that students require. The college succeeded in reducing the cost of printing so students experienced a massive reduction. The discounts were part of the strategy to increase acceptance but a lot of students felt that the college was discriminating against a core student body by giving a ten percent discount for card use. Another reason for the resistance was due to the fact that WIT was the first college to implement this type of card in Ireland. Other colleges considering implementing the Smart-card systems will be able to see the key benefits of the technology and they will be able to avoid the problems encountered by WIT. There is a sense of prestige or image for students of WIT to have this card because the WITCard was the first chip student card and is currently unique in comparison to other institutes. Some of the initial resistance was also caused by students who were angry that the majority of transactions on-campus were card-based, resulting in long queues for the few remaining cash tills. The benefits of mixed cash as opposed to a noncash system are not as high as there are still cash handling problems with the 
mixed system. Currently, the WIT has fifty percent of all their money on campus in electronic cash (e-cash), and fifty percent of it in cash. WIT is expecting that within the next few years it will increase to between seventy and seventy five percent e-cash. The driving factor for the card at the moment is the ten percent discount. Students will actually use the card if they get a ten percent discount and plus the fact that a lot of the college's operations at the moment, such as the sandwich bar, the new library, the campus bookshop, will not accept cash which means that every student or staff member at some stage has to use their card. The card is compulsory, in that it is a standard college identification (ID) card, therefore the card operates within a 'closed environment' effectively eliminating choice within the college and usability off-campus.

WIT has an acceptance agreement with all of their cardholders (both students and staff), that the college will not release any information that is stored on the cards or in the back-office account without the cardholder's written permission. The only exception to this is, if a student or staff member's health is at risk. Access will only be issued when there is clear evidence that the health of a student is at risk, for example if the student was missing and the police wanted to see where the student last used the card. Initially, the students were protesting because it was felt that the card was an intrusion on their privacy and that the college was monitoring the users spending habits and deducting library fines automatically from the user accounts (which was the case) during the Summer. Under the conditions of the privacy agreement formed with the student body, WIT can not, if there is a fine outstanding in the library, deduct funds from users it is currently the responsibility of the library to enforce the payment of fines, not the card office (see Table 1 for a summary of the findings).

\begin{tabular}{|c|c|c|c|}
\hline \multicolumn{2}{|c|}{ Smart-Cards } & \multicolumn{2}{|c|}{ Educational Case: The WITCard } \\
\hline Advantages & Disadvantages & $\begin{array}{r}\text { Problems } \\
\text { Encountered }\end{array}$ & $\begin{array}{l}\text { Benefits } \\
\text { Derived }\end{array}$ \\
\hline \begin{tabular}{l}
\multicolumn{1}{c}{ Security: } \\
Multiple factor \\
authentication \\
[Armstrong, 2001; \\
Lewis, 2002] \\
Processing \\
capabilities \\
Self containment \\
Tamper resistant \\
[Lett et al., 2002],
\end{tabular} & $\begin{array}{l}\quad \text { Privacy: } \\
\text { Loses anonymity of } \\
\text { cash } \\
\text { [Beverly, 2002]. }\end{array}$ & $\begin{array}{l}\text { Cost: } \\
\text { The cost of the } \\
\text { system was } \\
\text { important early on } \\
\text { but WIT wanted } \\
\text { the best system } \\
\text { they could buy- } \\
\text { raised finance and } \\
\text { support from } \\
\text { different sectors. }\end{array}$ & \begin{tabular}{l}
\multicolumn{1}{c}{ Security: } \\
Fewer muggings \\
of students. \\
Less chance of \\
robberies in \\
college shops as \\
there is no cash. \\
Security is \\
important and \\
magnetic stripes
\end{tabular} \\
\hline
\end{tabular}




Access to memory
controlled
Lock-down
[Lewis, 2002]
Copy proof
Gemplus, 2003]
PKI [Bassett,
2001]

$\quad$ Memory Size:
Greater than
magnetic stripes
[Rastogi \& Das,
2002]
Allows multiple
applications
[Miller, 2002]
Biometrics \&
Encryption

$\quad$ Portability:
Size of a credit
card
[Pikrammenos,
$2002]$
Not limited to
one location
[Coia, 2002].

Multiple
Applications:
Processing power
Lower costs

\section{Multiple}

Applications:

Who manages the card?

[Newman \& Sutter, 2002].
In house system.

Planning was very important in saving later expenses such as migration costs.

Standardisation:

WITCard is compatible with certain standards but there needs to be ISO accepted standards.

Important to be EMV compliant. Modern chip obsolete by 2005 .

\begin{tabular}{l|}
\multicolumn{1}{c|}{ Training: } \\
Training courses \\
for operators \& \\
staff. \\
Promotion and \\
marketing for \\
students with \\
pamphlets and \\
videos.
\end{tabular}

\section{Resistance}

Usage:

Fears over security of money Privacy of information Tracking of student's use Length of queues Card was used for core services

No choice

Convenience:
Provides
convenience

\begin{tabular}{l}
\multicolumn{1}{c}{ Cost: } \\
Deployment \\
Readers
\end{tabular}

can be 'skimmed' too easily.

Pin only used for access to campus residences as PIN's slow queues. Multiple applications only important where fraud is a problem.

Cost savings:

Reduction in the cost of handling cash - 12 to $15 \%$. Students get a $10 \%$ discount on all smart card purchases.

Do not have to hire cash handling company.

\section{Convenience:}

Replaced all other cards students had to carry around

\section{Portability:}

Students are not limited to one location with the card. 


\begin{tabular}{|c|c|c|c|}
\hline $\begin{array}{l}\text { Ease-of-use } \\
\text { Familiar method } \\
\text { [Gemplus, 2003] } \\
\text { Wallet size }\end{array}$ & $\begin{array}{l}\text { Replacing former } \\
\text { equipment } \\
\text { Training }\end{array}$ & $\begin{array}{l}\text { information on } \\
\text { card. }\end{array}$ & \\
\hline $\begin{array}{l}\text { Cost Savings: } \\
\text { No telephonic } \\
\text { [Newcombe, } \\
\text { 1999] } \\
\text { Timesavings } \\
\text { [Miller, 2002], } \\
\text { Eliminates paper } \\
\text { handling costs } \\
\text { [Choi et al., 1998] } \\
\text { Cash handling } \\
\text { [Kalakota \& } \\
\text { Whinston, 1996] } \\
\text { More reliable and } \\
\text { longer lasting } \\
\text { [Chanson, 1998; } \\
\text { Petri, 2002] } \\
\text { Easily updated } \\
\text { without reissuing } \\
\text { [Gemplus, 2003] }\end{array}$ & & $\begin{array}{l}\text { Initial Problems: } \\
\text { No major } \\
\text { problems, some } \\
\text { minor problems } \\
\text { such as card not } \\
\text { reading }\end{array}$ & $\begin{array}{l}\quad \text { Productivity: } \\
\text { Makes job of } \\
\text { college staff } \\
\text { easier, for } \\
\text { example, time and } \\
\text { attendance. }\end{array}$ \\
\hline $\begin{array}{l}\text { Micro-charging: } \\
\text { Ideal for small } \\
\text { purchases } \\
\text { [Karppinen, } \\
2000] \text { ] }\end{array}$ & & & $\begin{array}{l}\text { Transaction } \\
\text { Times Reduced: } \\
\text { Special queues for } \\
\text { students using } \\
\text { smart cards, is } \\
\text { faster as no } \\
\text { change involved. }\end{array}$ \\
\hline
\end{tabular}

\section{Table 1: Case Findings}

\section{DISCUSSION}

Presently, WIT is using a 'Schlumberger Payflex' manufactured two kilobyte contact chip on their Smart-cards. The college was using magnetic stripe cards prior to the introduction of the WITcard as well as barcodes and felt that it was important not to implement change too quickly. For this reason, to date, all three methods have been retained on the card, which are used at different outlets. WIT's plan over the next two years is to transfer all of the applications onto the chip because " ...the chip is a much more secure system than the magnetic stripe". The college has never had a breach in the security with the card to date, which is very important as “...you can never 
guarantee security". WIT also plan to introduce a contactless technology using the 'Phillips MiFare Contactless' technology system, for access control and time and attendance. Contactless technology plays a significant part in Smart-card systems particularly in areas such as access control and transportation, resulting in benefits such as speed of transactions which is ideally suited to busy processes in WIT such as for example, taking the attendance of students. The weakness of contactless technology is that banks have yet to adopt it as a secure standard and it is really only suitable for lowlevel security applications like access control and transit where a large amount of money is not required. The college decided on a Linux based system with Oracle for the operating system because Microsoft was “...a costly product due to licensing arrangements....”. The college also found Linux to be a very robust system, which worked very well. Originally, WIT would have bought an operating system from a vendor but there was nothing available in Ireland, the products available in the UK were very poor and the US systems were changed frequently so the college decided to just build their own. In addition, the college would also have had to learn the proprietary system, thus delaying the delivery of the system and making it harder to develop applications.

WIT is able to store their e-purse on the WITCard chip but the cards are in a closed environment. Currently, the purse is stored online in a back-office database. The college researchers identified a number of problems when students' downloaded money onto the chip as when the end users lost their card, they would automatically lose their money. Due to the back office account (saving the different transactions), the college can replace the card and replace the money instantly. It is possible for WIT to download money onto the chip. This functionality will be implemented in the future when management decides to extend the usability of the Smart-card to off campus, as a form of payment for public transport for example. This would involve the students downloading a small amount from their main back-office account onto the chip for use outside the campus.

5. CONCLUSION

Clearly, there are a number of lessons that may be learned from the WIT Smart-card implementation. Firstly, it is evident that in this current environment security issues are to the forefront of user's concern when utilizing Smart-card technology. Every application on the campus is currently online so there is no need to store money on the chip which 
ultimately provides greater security to the end-users, as the main money is in the back-office account. The WITCard is secure which is important because if a student does not feel the card is secure they will not use it. Although, the audit trail generated by such a card remains a limitation of the technology. Secondly, ease of use has become another key factor when considering the introduction of new technology to any environment. User's expectations have heightened over the last number of years as organizations strive to manage customer needs through the provision of products, services, information and most importantly ongoing support. Smart-card technology is no different, customers have come to expect the quickest and easiest means of doing business and for Smart-cards this means synthesizing a range of functionality into one single, portable, multipurpose card. Finally, it is evident from the WIT case that in order for user's to accept and effectively utilize the new technology, they must be provided with some kind of incentive to encourage them to do so. In this instance, students were offered a 10 percent discount on campus for using their cards. Considering the average demographic and income status of the student body, offering discounts was the key strategic move in promoting the widespread use of the WITCard. While the WIT Smart-card implementation experienced some problems, it seems that WIT is focused on a 'smart future' with plans for the card to store applications, "...but you have to crawl before you walk and there is no point in going too far too quick”.

\section{REFERENCES}

Alder, E., (2002), Smart Card Technology - Hong Kong: Legal Issues in Smart Card Technology,Computer Law \& Security Report, Vol. 18, no. 2, Pg $120-123,2002$.

Armstrong, I., (2001), Smartcards: Still a Gamble?, SC Magazine, October 2001, Second Feature.

Banerjee, R., (1997), Smart Card Standards and Electronic Purse, A review paper, Card Dynamics Consultant to THE SMART CAMPUS project, May 1997

Berney, L., (2000), Smart Cards Begin to Arrive in B2B E-Commerce, ECommerce World Magazine, 02/01/00.

Beverly, P. et al., (2002), Secure Personal Identification Systems: Policy, Process and Technology Choices for a Privacy-Sensitive Solution, Smart Card Alliance White Paper, February 2002.

Blakey, E. \& Saliba, C., (2000), Smart Cards Stack the E-Commerce Deck, E-Commerce Times, December 28th, 2000.

Briney, A., (2002), A Smart Card for Everyone?, Information Security Magazine, March 2002, www.infosecuritymag.com/2002/mar/cover.shtml 
Chandak, A. \& Shah, A., (2001), E-governance accelerates usage of smart cards in India, Express Computer Magazine.

Choi, S. \& Whinston, A., (1998), Smart Cards: Enabling Smart Commerce in the Digital Age, CREC/KPMG White Paper, May 1998.

Coleman, A., (1998), The Future of Smart Cards: Java Card API, Sun Journal, Vol. 1, No. 4.

Day, G. \& Fein, A., (2000), Shakeouts in the New Economy, Wharton Working Papers, 2001, hops.wharton.upenn.edu/people/faculty/day.html.

Dearing, J., Meyer, G. \& Kazmierczak, J., (1994), Portraying the new: communication, Science Communication, 16, 11-42.

Gemplus, Inc., (2003), Smart Card Basics, http://www.gemplus.com/basics/what.html

Hebert, M. \& Benbasat, I., (1994), Adopting Information Technology in Hospitals: The relationship between attitudes/expectations and behaviour, Hospital and Health Services Administration, 39(3), 369-383.

Hovenga Fancher, C., (1997), In your pocket: Smartcards, IEEE Spectrum, February 1997.

Kapoor, R., (2002), Enhancing customer value using smart cards, Cards Worldwide, 18/07/2002.

Karppinen, L., (2000), Attacks related to the smart card used in electronic payment and cash cards Tik-110.501 Seminar on Network Security http://www.tcm.hut.fi/Opinnot/Tik110.501/2000/papers/karppinen.pdf

Katz, et al., (2002), Smart Cards and Biometrics in Privacy-Sensitive Secure Personal Identification Systems, A Smart Card Alliance, May 2002.

Lee, J., Walsh, E. \& Gazala, M., (2000), Debit Cards Will Fuel Teen Online Spending, Consumer Technographics Brief, 2000, Forrester Research.

Lett, R., Brown, D. \& Horrell, B., (2002), Smart Cards, CS-590 Computer Security Planning \& Engineering, Spring 2002.

Mcelroy, D. \& Turban, E. (1998), Using Smart Cards in E-Commerce, International, Journal of Information Management, 1998, Vol 18, No 1.

McGraw, G. \& Felten, E., (1999), Securing Java: Getting Down to Business with Mobile Code, 2nd Edition, Published by John Wiley \& Sons 1999

Manchester, D., (1997), Smart Cards: Key to Cashless Economy?, The Futurist, Jan/Feb., 1997, Pg 29-32.

Mäntylä, M., (2001), Smart card payment and risk scenarios, T-110.501 Seminar On Network Security 2001.

Miller, T., (2002), How Smart Are Smart Cards?, Entrepreneur.com, March 11,2002

Moore, S., (1994), Understanding innovation in social science delivery systems, Health Marketing Quarterly, 11(4), 61 -74.

M'Raihi, D. \& Yung, M., (2001), E-commerce applications of smart cards, Computer Networks, Vol 36, 2001, Pg 453 - 472. 
Newing, R., (1998), Understanding Smart Cards, PC Support Advisor, Update 117, July 1998, Pg 7 - 12

Papameletiou, D., (1999), Study on Electronic Payment Systems for the Committee on Economic and Monetary Affairs and Industrial Policy of theEuropean Parliament, Vol I: Main Report, EUR 18753 EN.

Plouffe, C., Vandenbosch, M. \& Hulland, J., (2001), Intermediating technologies and multi-groupadoption:a comparison of consumer and merchant adoption intentions toward a new electronic payment system, Journal of Product Innovation Management, Vol 18, Issue 2, March 2001, Pg 65-81.

Pohlmann, N., (2001), Smart Cards: The Authentication Solution for the Ebusiness User, Network Security, Vol 2001, Issue 4, 1 April 2001, Pages 12-15.

Punishill, J. \& Shevlin, R., (2001), Credit Card Issuers Need A New Approach To Online Security, TechStrategyBrief, July 2001, Forrester Research.

Rastogi, L., \& Das, P., (2002), Re-Engineering Educational Institutions Through Smart Cards, SHTR Consulting Group.

Rogers, E., (1995), Diffusion of Innovations, 4th edition, New York: Free Press, 1995.

Sorenson, D., (2001), Smart-Card Devices and Applications, DELL White Paper, January 2001.

Tornatsky, L. \& Klein, K., (1982), Innovation Characteristics and Innovation Adoption-Implementation: A Meta-Analysis of Findings, IEEE

Transactions on Engineering Management, EM-29, 1, February, 28-45.

Truman, G., Sandoe, K. \& Rifkin, T., (2003), An empirical study of smart card technology, Information \& Management, Vol 40, Issue 6.

Urien, P., (2000), Internet card, a smart card as a true internet node, Computer Communications, $\mathrm{Vol} 23$, pages 1655 - 1666.

Wallis, A., (2002), Interview with a smart card, Card Technology Magazine,25/09/2002,http://www.cardsworldwide.com/Tmpl/article.asp Wood, C., (2002), Is That a Smart Card in Your Pocket?, PC Magazine, www.pcmag.com/article2/0,4149,1925,00.asp 